\title{
Anticipating the Reader's Problems and the Automatic Generation of Paraphrases
}

\author{
Nils Lenke \\ Gerhard-Mercator-Universitaet-GH Duisburg FB3 - Computerlinguistik \\ Lotharstr. 65, D-47048 Duisburg \\ voice: +49 (0)203-379-2007; c-mail: he233le@ unidui.uni-duisburg.de
}

\section{ABSTKACT}

The notion of paraphrase is discussed and compared with the similar notion of periphrase. The role of paraphrases in oral communication is described, and the results of a study on the role of paraphrases in texts are given. li nally, a system which models the use of paraplarases in texts is described.

\section{PARAPHRASES IN DIALOgUeS}

If you look at ordinary dialogues you will find that communication failures - i.c. different types of misunderstandings - happen frequently, cf [Ringle \& Bruce 1982]. One important technique for the participants of the communication to solve these problems is paraphrasing, that is, saying it again in other words. Paraphrases can be offered by the hearer ("Is it this what you want to say: ...") or requested from the speaker by the hearer ("Huh"? I don't understand."). These kind of paraphrases may be called communicative or pragmatic paraphrases.

\section{OTHER NOTIONS OF "PARAPIIRASE"}

Notions of "paraphrase" exist which differ from the one presented above. In linguistics, especially Transfonmational Grammar, cf. e.g. (Smaby 1971), (Nolan 1970), the paraphrase relation is induced by the rules of the language system. Two formulations count as paraphrases of each other if they can be derived from a common deep structure, c.g. the active and the passive version of a sentence. So, the paraphrase relation is completely independent of the situation and communication participants. This view has been heavily criticised, $\mathrm{cf}$. (Ungehcuer 1969).

In $\mathrm{Cl}$, the generation of a surface form from a meaning representation is sometimes called paraphrase generation, especially if different surface forms can be generated for the same meaning representation. An anbiguity exists here, because the paraphrase relation can be meant to hold (a) between the meaning representation and the NL text derived from it or (b) between two alternative formulations which could both be derived from the meaning representation.

I will simply call case a) "generation" because that is what it means: deriving a text from an underlying meaning representation. Case b), excmplified by (Goldman 1975) and most work in the area of Meaning-Text Models, cf. e.g. (Iordanskaja, Kittredge \& Polguère 1991), (Mel'cuk 1981), stresses the possibility of an alternative formulation which could be uttered instead of another formulation, whereas in section 1 we talked of paraphrasing as uttering a formulation in addition to another formulation. To differentiate between these cases I will not call case b) paraphrase but - in accordance with classical hetoric - periphrase.

\section{RELATED WORK IN CL}

Quitc a lot of work exists on the use of paraphrases in conncction with NI,-database frontends, cf. e.g. (McKeown 1979), (Meteer \& Shaked 1988). The formal representation gained from the user's query is translated back to NL, again and the user is requested to indicate if the system understool him correctly. This fits nicely into the framework from section 1 .

$\Lambda$ s indicated above, much of the work presented under the title "paraphrase generation" should better be called "periphrase generation". Reiter's (1990) system IPN generates - depending on the user model entry for the problematic word "shark"- onc of the following alternative formulations:

1a) There is a shark in the water

1b) There is a dangerous fish in the water

Similarly, the system WISBISR (Iloracek 1990) generates one of the following formulations, where the problematic word is "Notgroschen" (rainy day fund):

2a) I Iaben Sie einen Notgroschen? [Do you lave a rainy day fiund?]

2b) llaben Sic cin Sparbuch mit zwei Nettomonatseinkommen? [Do you have a savings account with two month's net income?]

In the terminology advocated here, the b)-cases are periphrases of the a)-cases. Real formulations with paraphrases would look something like this:

1c) There is a shark, that is, a dangerous fish, in the water 2c) Ilaben Sie einen Notgroschen, d.h. ein Sparbuch mit zwei Neltomonatseinkommen?

[Do you have a rainy day fund, that is, a a savings account with two month's net income?

It will be discussed below under which circunstances such utterances could be superior to the a)- or b)-cases.

\section{ANTICIPATION OF MISUNDER-} STANDINGS AND THEIR AVOIDANCE Turning now to the generation of written texts it seems to be a bit paradox to do this in connection with paraphrases, since in section 1 we showed them to be a phenomenon of clialogue, i.c. oral communication. But paraphrases do play a role in texts as well, especially when anticipation is considered. "This can already be noted in the case of spoken language. $A$ well known molcl of the production of spoken language is the one of Levelt (1989). One of its main aspects is the existence of control and revision loops which can be used to monitor the planned or realized utterance and detect errors in it. So, part of the errors can 
already be anticipated in advance by the speaker before the hearer even gets to hear the problematic utterance.

When we now turn to written language again, we also find the concept of problem anticipation and revision loops. These are of even greater importance here because the reader normally has no chance of signalling his problems with a text to the author. So, the author has to take the role of the reader and anticipate problems he might have with the text. Most models of the writing process thus include a revision loop, $\mathrm{cf}$. the well-known model of Hayes and Flower (1980). In CL, this mechanism is known under the name anticipation-feedback loop, cf. (Jameson \& Wahlster 1982), and in the form of revisionbased generation systems, cf. (Gabriel 1988), (Vaughan \& McDonald 1986).

What are the options for an author if he detects trouble sources in his planned text? Je may choose to

a) add a meta-comment; the addition of meta-comments (Sigurd 87) like "loosely speaking", "to say it frankly", "a kind of", etc. is often used to indicate to the reader how to interpret a problematic utterance.

b) add a further, alternative formulation (a paraphrase) or c) replan the text (formulate a periphrase).

The rest of the paper will solely deal with b) and c). What was said so far leads to the following hypothesis:

Writers of texts anticipate reader problems, and, in some cases, include paraphrases to avoid these troubles.

\section{A STUDY ON PARAPHRASES IN TEXTS} A study, cf. (Lenke, in preparation) for details, was conducted in order to find occurrences of paraphrases in texts and analyse them with the aim of checking the hypothesis mentioned at the end of section 4 .

First, a small corpus of German texts was scanned manually for paraphrases; the major results were:

- Paraphrases of the kind described above can indeed be found. Typical examples of such paraphrases are ${ }^{1}$ :

(3) "... introduces the notion of multiple inheritance - that is, the ability of a class to have more than one directbase class - and presents ..." [p. 182]

(4) "A language is said to support a style of programming if it provides facilities that make it convenient (reasonably easy. safe, and eflicient) to use that style." [p. 14]

- only part (roughly 50\%) of the paraphrases are announced by indicators like "that is", "in other words", parentheses or hyphenation. The other paraphrases are simply added as an apposition to the paraphrased term.

- the total number of paraphrases differs vastly between text types: in narrative texts few and mostly unannounced paraphrases occur; in more technical texts,

1 the following English examples all stem from [Stroustrup 1991] and were collected just to be English examples suitable for the presentation in this paper. especially manuals and introductory texts, many paraphrases

In the second phase of the study, the IJIMAS corpus of German ( 1 million running words from 500 texts of different types) was then scanned automatically for the most common German paraphrase indicators (a.o. "d.h.", "das heißt", in anderen Worten", "also") Well above 1000 occurrences of paraphrases were found and analysed. The results of the first phase could be confirmed. Other results were:

- the syntactic form of the paraphrases is in most cases either a complete sentence (in which another complete sentence is paraphrased) or an apposition, which belongs to the same syntactic category as the word/phrase it belongs to.

- Paraphrases are directed to quite dilferent problem sources which were anticipated by the author. Among the different types found were the following:

1. problematic lexical items

a) unknown words (cf. examples 3 above)

b) ambiguous words;

c) words of abstract nature which obtain their concrete meaning through the context in which they occur. The paraphrases indicate the direction in which this concrete meaning should be searched. Cf. example 4 above.

2. reference problems

a) ambiguous anaphoric references, e.g. pronouns;

b) anaphoric expressions where the referent is very distant (causing memory problems)

c) missing knowledge to understand referring expression.

3. problems induced by rhetoric figures (melaphors, metonymy).

4. inference problems

a) problems of aspectualization. (only some aspects of the meaning of a word are relevant in a certain context).

b) problems of logical inferences. (Obvious and relevant inferences from an utterance might be too difficult to draw by the intended reader).

Thus, one can conclude that paraphrases are indecd used by authors to avoid anticipated reader problems. These problems can be of all those types that have since long been noticed in the area of NL, understanding.

\section{IMPLEMENTED MODEI}

The next step in the project was to design and implement a model which describes this use of paraphrases in texts. It should answer the following questions:

- Ilow can problems of the reader be anticipated?

- Under which circumstances are paraphrases the adequate answer to this problems (and not, say, periphrases or meta-comments)?

- How can paraphrases be generated?

Three well known approaches to NL generation are combined in the model : user modelling, anticipation-feedback 
loops and revision-based text generation. Its architecture is shown in Irig 1:

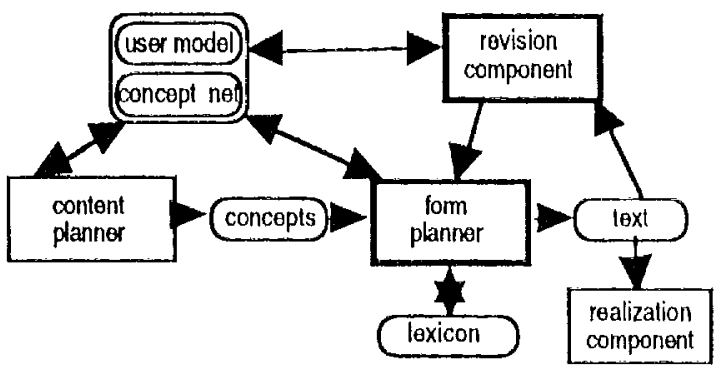

Fig 1: the system's architecture

The main feature is the revision/ anticipation-feedback loop, which is highlighted in the figure.

'Ihe types of problems for which paraphrases can be generated by the system are restricted to problems which occur during lexicalization and involve only conceptual knowledge (no assertional knowledge) in order to restrict complexity. These are (in terms of section 5) the types $1 \mathrm{a}, 1 \mathrm{~b}, 3 \mathrm{a}$, and - with restrictions - $4 \mathrm{a}$, which are (together with type 1c) by far the most frequent types occurring in natural texts. The other types could principally be dealt with in a similar fashion. A corpus of about 25 eximples, all collected from the same source, the manual for the Apple Macintosh operating system 7, were used ats a basis. 'The advantages of this approach is that all examples are based on a common domain (knowledge about Macintosh computers), so that a common lexicon and a common knowledge base can be used for all of them. Of course, the techniques and principles used are not restricted to this set of examples and could be transferred to other domains.

\subsection{An example}

To demonstrate how the components of the systems work together consider example 7, from the corpus on which the system is based:

(5) Alle Macintosh Modelle sind mit einem Steckplatr. oder Anschluß für Geräte atusgestattet, der die SCSTSchnittstelle (Small Computer System Interface) unterstütat. [all Macintosh models are equipped will. a slot or idterface for SCSI-devices]

The content planner of the system is only implemented as an oracle, that is, it is preset to produce the concepts to be formulated and to answer certain questions by the form planner as if it were a full-fledged content planner in a complete NI, system. In the concrete example, it would first inform the other components that the linguistic context of the target item consists of the concept Macintosh (the only concept that precedes slot in the planned sentence) and would then request the form planner to verbalize the concept slot.

The form planner would then look up the first possible linguistic items for the concept slot in the lexicon. The lexicon not only incorporates information about the linguistic items but also about their connections to items of the concept-base. These connections take the form of $700 \mathrm{M}$-schemata, as known from the WISBER system, cf. (Iloracek 1990). Briefly,
Z)(OMs are links between concepts or sinall substructures of the concept-network on the one hand and linguistic items (words) on the other hand.

In our example, the first choice to verbalize slot would be 'Anschluß'. This proposal is then put forward to the revision component which tries to anticipate reader trouble. To do this, it uses a simple user molel, which employs the well known stereotype approach (Wahlster \& Kobsa 1989). All concepts, lexical entries and \%OOMs belong to one of the three categories common vocabulary, computer jargon and Macintosh specific jargon. The static part of the user model then simply consists of three variables which indicate if the intended reader is expected to be familiar with the respective jargon.

This user models differs from other approaches because it allows the special value "?" which indicates incomplete (you never know all about the readers) or inconsistent (a text can be meant simultaneously for novices and experts) knowledge. From this static part of the user model a default value can be calculated which can be overridden through leaming (sce below). To be a bit more exact, two values are calculated in a kind of "worstcase-analysis" due to the "?" values in the user model. In our example two 7OOM-schemata exist for slot:

slot $\leftrightarrow \rightarrow$ 'Anschluß'

slot $\leftrightarrow->$ 'Stcckplatz'

'Anschlub' (and the \%OOM connecting it with slot) is marked Macintosh, the alternative lexical entry 'Steckplatz' is marked common. So, if the user model indicated that Macintosh vocabulary was yes, the revision component would judge the wording 'Anschlub' ok and the realization component would output

"Alle Macintosh Modelle sind mit EINEM ANSCILUSS für Geräte ausgestattet, der die SCSI.Schnittstelle unterstüzt."

But now consider a user model which indicates that the knowledge of computer and Macintosh jargon is known to be no. Of course, the revision component would indicate that the term 'Anschluß' cannot be used. A possible solution would be to generate a periphrase, i.e. replacing 'Anschluss' by 'Steckplatz' which would be the next choice of the forn planner. This would then be accepted by the revision component. In some cases, however, this would be less than perfect: (a) if the concept has repeatedly to be verbalized in the course of the text, (b) if thene are stylistic reasons to use the first choice term (here: 'Anschluss'), (c) if there are pedagogical reasons to use the first choice.

(a) consider a case in which the periphrase is a longish definition. It would be a bore to replace a short term by this definition 15 times around the text. So you do it once and simply use the now learned term in the rest of the text.

(b) Certain texts can loose their "fcel" if stripped of e.g. the expert vocabulary of a certain area.

(c) Manuals and introductory texts are often meant to teach the vocabulary in addition to the concepts. In this case it would be nonsense to replace the to-betaught vocabulary by casier "terms". 
All these conditions can only be determined by the content planner (demonstrating the need for an interaction between form planner and content planner); in the system, the form planner asks the content planner, which works as an oracle, i.e. gives the correct answers (by forwarding the questions to the human operator). If one of the conditions holds, it would be unwise to formulate a periphrase. The next choice of the form planner would then be to ask the content planner to completely replan this part of the text, namely to include a new sentence defining the problematic term. The system output looks like this:

ANSCHLUSS BEDEUTET STECKPLATZ. AIle Macintosh Modelle sind mit EINEM ANSCHLUSS für Geräte ausgestattet, der die SCSI-Schnittstelle unterstutzt.

Even this solution doesn't work in some cases and that is where paraphrases come into play. If stylistic variation is necessary or if the problematic term is embedded in the definition of still another term it is the right place to use a paraphrase:

Alle Macintosh Modelle sind mit EINEM ANSCHLUSS D.H. EINEM STECKPLATZ für Geräte ausgestattet, der die SCSIschnittstelle unterstutzt.

\subsection{A second example}

Just another path may lead to the generation of paraphrases for an unknown term, as the next example will show:

(6) "Mit der Maus - dem Gerät zum Zeigen und Klicken werden die meisten Macintosh Funktionen aktiviert." [With the mouse - the device for pointing and clicking - most Macintosh functions are activated]

Fig. 2 shows the part of the conceptual network underlying this example:

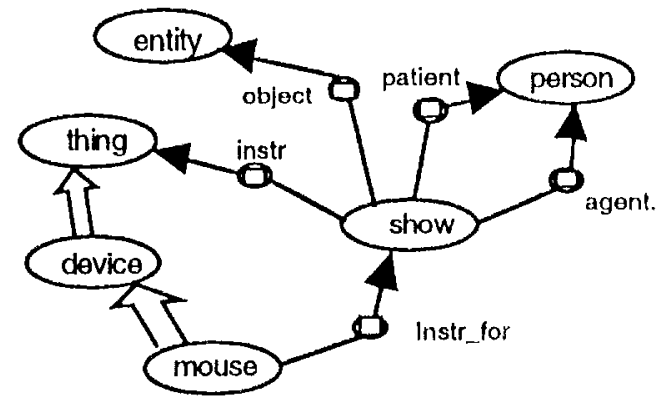

Fig. 2: the concept mouse

The term 'Maus' is classified computer jargon and may not be known to the user. The replacement of the term by a definition (no synonym is available) yields the danger of encouraging false conversational implicatures by the reader, cf. (Reiter 90). Consider a user model where computer and Mac jargon are indicated as "?". A worst case analysis by the revision component would show that the use of 'Maus' is inappropriate because some novices wouldn't know the term, but that the periphrase 'Gerait zum Zeigen (und Klicken)' is inappropriate either, because some experts will know the term 'Maus' and conclude from its absence that some other pointing device, but not the mouse, was meant. ${ }^{2}$ So, a paraphrase would again be the best solution. The system thus generates:

Mit DER MAUS D.H. DEM GERAET DES COMPUTERSYSTEMS ZUM ZEIGEN werden die meisten Macintosh Funktionen aktiviert.

Ilere the paraphrase is a definition of the form per genus proximum et differentia specifica which results from part of the systems' concept net shown in figure 2. The system is capable of generating two other forms of definitions (paraphrases), definition by antonymy and by enumeration.

6.3 Detection and resolution of ambiguity Up to now, only the problem type of unknown words has been discussed. Due to lack of space only one more problem type which leads to the gencration of paraphrases can be discussed, namely the problem of ambiguous words. This problem type has since long been discussed in the area of NL understanding. Techniques for its solution include the use of spreading-activation mechanisms working on conceptual networks, cf. (I lirst 1987). This can now be used for the purpose of problem anticipation. We just try to disambiguate terms and interest ourself in the cases in which it fails: these are candidates for paraphrase generation. Cf. the following example from the corpus:

(7) "Das aktive Fenster steht im Vordergrund[,] also vorallen anderen geölfneten Fenstern."

[The active window stands in the foreground, that is, in front of all other open windows]

Here, for beginners two readings of 'im Vordergrund' are possible: a literal (this is the correct reading) and a metaphorical (in the sense of "important, to be regarded") which are equally propable. The revision component comes to this conclusion by conducling a worst case analysis using the concept net, an activation-spreading algorithm and the user model. Only those concepts and links that ane known to a reader may lorward energy, so in the case of "?" values in the user model, both alternatives have to be tested (hence the term "worst case anaysis"). If comparable quantitics of the activalion energy induced into the net by the linguistic context find their way to both (or more) readings (concepts) of the ambiguous terms it is concluded (and then indicated to the form planner by the revision component) that the ambiguity might not be resolved by the realer. Then, a paraphrase could eventually (in a process similar to that described above) be generated, delining the correct reading. See (Lenke, in preparation) for details of the spreading-activation mechanism used.

\footnotetext{
2 cf. Reiter's (1990) "dangerous fish" vs. "shark" example.
} 
6.4 Two more features of the system These can only be discussed briefly. Sec (I enke, in preparation) for details.

- Paraphrases of the aspectualization type (see above, section 5) can also be generated. Ilere, only one of the defining elements of a concept, either the superclass (genus proximum) or one of the roles (differentiae) is verbalized. At the moment, this kind of paraphrase is only generated when requested by the content planner; in the future, it will be necessary to model the anticipation of inference processes based on relevance by the reader to correctly predict the need for such paraphrases. An example from the corpus, the underlying concept net and the equivalent produced by the system are shown below.

(8) Durch das Klicken werden die Objekte aktiviert, d.h., sic werden num schwarz (oder in einer anderen liarbe) dargestell und somit heryorgeholxn. [Caused by the clicking the objects are activated, that is, printed in black (or another colour) and so highlighted]

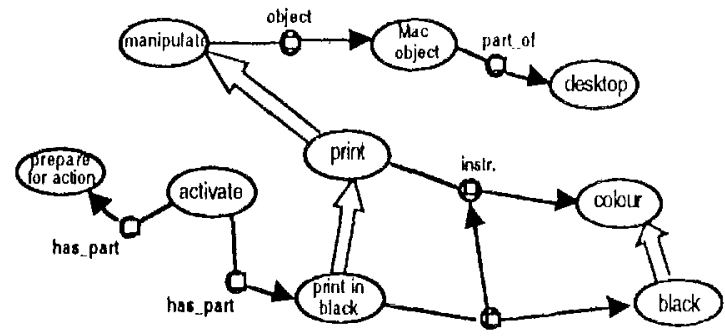

Fig. 3: the concept activate

Durch das Klicken werden die objekte AKTIVIERT D.H. SCHWARZ DARGESTELLT .

- if a paraphlrase for an unknown term has been generated, it can be concluded that the reader now knows this term. This is modelled by an active component of the user model which overrides the default values computed by the static component decribed above. So, only for the first (or first and second) appearence of a term a paraphrase is generated. Thereafier the term is simply used. This nicely mimics the observations made in naturally occurring texts.

\section{IMPLEMENTATION DETAILS}

The system is implemented in an object-oriented programming language and runs on Macintosh computers. It contains a conceptual network similar to KL-ONE, consisting of approx. 130 concepts and 65 roles. Its lexicon consists of 70 \%OOM schemata and 50 lexical entries.

\section{FUTURE WORK}

Some possibilites for fulure work have already been indicated in the text, most notably the embedding of the procedures described into a full-fledged NL-sysiem. 'The approach described could also be transferred to other kinds of possible reader problems as enumerated in section 5 . Since these are the problem areas of NL-understanding, algorithms exist which try to solve the understanding problems posed by these language features. These could be used to predict failure (as was demonstrated above for the activation-spreading mechanisms)

\section{KWFERENCES}

Gabriel, R.P. (1988). Deliberate Writing. In: McDonald \& Bolc Eds. Natural Language Generation Systems. pp.1-46.

Goldman, N.M. (1975) Conceptual Generation. In: R.C. Schank Id. Conceptual Information Processing.

Ilayes, J. R. \& L. S. Flower (1980)). Identifying the Organization of Writing Processes. In L.W. Gregg \& E.R. Stcinberg Eds. Cognitive Processes in Writing. pp. $3-30$.

Yirst, (r. (1987) Semantic Interpretation and the Resolution of Ambiguity.

Iloracek, II. (1990). The Architecture of a Generation Component in a Complete NI, Dialogue System. In Dale, Mellish, Zock Eds. Current Research in Natural Language Generation. pp. 193-227.

Iordanskaja, I.., R. Kiltredge \& Al. Polguère (1991). I.exical Selection and Paraphrase in a Meaning-'Text Generation Model. In Paris, Swatout, Mann lids. Natural Language Generation in $A I$ and $C L$

Janeson, A.\& W.Wahlster (1982). User Modeling in Anaphora Generation: Ellipsis and Definite Description In: Proc. of ECAI 82. pp. 222-227.

McKcown, K. R. (1979) "Paraphrasing Using Given and New Information in a Question-Answer System", in Proc. of the 7th Conference of the $A C \mathrm{C}$, I a Jolla, 1979, pp. $67-72$.

I.cnke, N. (in prep.). Paraphrasen - Iösungen für antizipiente Leserproblene bei der automatischen Textgenerierung. Dissertation, Univ. of Duisburg.

I.cvelt, W. (1989). Speaking. Irom Intention to Articulation.

Mel'cuk, I. A.. Meaning-'Text Models (1982): $\wedge$ Recent Trend in Soviet Linguistics. Ann. Rev. Anthropology 10:27 -62.

Metecr, M. \& V. Shaked (1988). Strategies for Effective Paraphrasing. Proc: of Coling '88. pp. 431 - 436.

Nolan, R. (1970). Foundations for an Adequate Criterion of Paraphrase.

Reiter, I: (1990). Generating Descriptions that Exploit a User's Domain Knowledge. In Dale, Mellish, Yock lids. Current Research in Natural Language Generation. pp. $257-285$

Ringle, M. II. \& B. C. Brucc (1982). Conversation lailure In Lehnert; Ringle Eds. Strategies for Natural Language Processing. pp. 203-221.

Sigurd, B. (1987). Metacomments in Text Gencration. In G. Kempen Ed. Natural Language Generation. pp. 453-461.

Smaby, R. M. (1971). Paraphrase Cirammars.

Stroustrup, B. (1991) 'The C+ + Programming Ianguage. 2d. Ixl.

Ungeheuer, (i. (1969) Paraphuse und syntaktische 'licfenstruktur. Folia Ling. 3. pp. 178-227.

Vaughan, M.\& D. Mcl Donald (1986). A Model of Revision in Natural Lauguage Generation. Proc. of the 24th Annual Meeting of the ACL. pp. 90-96.

Wahlster, W. \& $\Lambda$. Kobsa (1989) User Models in Dialog Systems. In $\Lambda$. Kobsa \& W. Wahlsterleds. User Models in Dialog Systems. pp. 4 - 34. 